\title{
Cultural Translation of Technologies in Ethiopia ${ }^{1}$
}

\author{
Setargew Kenaw ${ }^{2}$
}

\begin{abstract}
The principal objective of this article is to show how technologies would be reconstituted in the social and cultural milieu in which they function. Focusing on the period from the last decade of the $19^{\text {th }}$ to the mid-20 $0^{\text {th }}$ century, the aim is to discuss the cultural appropriation of technologies in the context of modern history of Ethiopia through exemplary ventures such as the first piped water supply, installing telephone lines, and introducing the first airplanes to the country. Mainly my endeavor being a study in philosophy of technology, sources supporting the core of my argument include books, newspaper articles, and popular lyrics narrating the adoption of specific technological artifacts in the country. The paper argues that, during technology "transfer" (a transfer across regions or cultures), technological artifacts do not only impact cultures but are also actively appropriated by them.
\end{abstract}

Keywords: cultural appropriation/reconstitution/translation, mediation, technology, technology transfer, Ethiopia

DOI: https://dx.doi.org/10.4314/ejossah.v13i2.5

\footnotetext{
${ }^{1}$ This article is an improved version of a chapter in my monograph entitled as Technology Culture Dialogue (Setargew, 2016). It also drew on an unpublished material titled Cultural Translation of Technological Modernization: Postphenomenology and Technological Mediation of Culture (Setargew, 2006).

${ }^{2}$ Assistant Professor, Department of Philosophy, Addis Ababa University, Email: setargew.kenaw@gmail.com, Tel: +251912086457, P.O. Box: 150166/Addis Ababa
}

This work is licensed to the publisher under the Creative Commons Attribution-NonCommercialNoDerivs License. 


\section{Introduction}

This article, covering the period between the end of $19^{\text {th }}$ to mid- $20^{\text {th }}$ century, inquires into how new technological artifacts were culturally reconstituted or appropriated in Ethiopia. Three states of affairs are selected for analysis: the introduction of the first ever piped water supply, telephone communications, and air transport in the country. The focus is on the initial responses to the introduction of these new technologies as major steps in domesticating or reconstituting them into the exiting social and cultural codes.

When dealing with human-technology interface, terms like "appropriation" and "reconstitution" could alternately be employed in general terms to elucidate the interaction in question. The culture-technology interaction spectrum consists of various forms of meanings - ranging from a perplexing relationship at an initial contact with a new technology, through a relationship of appropriation, to a seeming passivity that allows a technology to configure the culture. In this context, cultural appropriation or reconstitution of technology could again involve several strands of interaction. While a hammer might have been designed, for example, to force a material to take a certain shape, we may say we appropriate the same hammer differently when utilizing it creatively, such as using it to drive away a burglar or applying it symbolically in a court room. Appropriating or reconstituting a technology into a given cultural practice therefore implies a certain level of, to use Joseph Schumpeter's widely known term, "creative destruction."

The paper has four more sections. Section 2 discusses the notion of technology transfer according to varying theoretical perspectives and explicates key terms. Section 3 lays down the historical context of Ethiopia's "modernization"3 trends. Section 4, comprising the major segment of the paper, addresses how specific technological innovations were introduced and culturally translated. The last section, the conclusion, inquires further into the imports and significances of the mechanisms and points out possible theoretical implications.

\section{Problem Statement}

In fields such as the history of technology, philosophy of technology, and science and technology studies, a range of theoretical perspectives were formulated with the aspiration of conceptualizing how technological innovation could impact socio-

\footnotetext{
${ }^{3}$ Modernization here refers to technological modernization in particular. It does not thus dare to enter into the distinction between modernization on the one hand and the ideas of modernism and modernity on the other - see Elizabeth Wolde Giorgis's (Elizabeth, 2010) superb discussion on the distinction with particular reference to the Ethiopian context. 110
} 
cultural phenomena and how the latter could domesticate or indigenize technologies. Most studies on technology and culture conceptualize the "movement" of technologies and technical skills from one part of the world to the other as technology "transfer," emphasizing on the "impact" aspect. Let me take a few examples. According to Lewis Mumford, the historian of technology, for any society to attain a certain level of technical development there should be first the "cultural preparation." Mumford (1934: 4) argues that any major technical innovation must be supported by social and ideological preparation. He therefore contends that our understanding of "technics" in the modern world must be based on our understanding of "the culture that was ready to use them and profit by them so extensively."

This line of conviction led Mumford to advocate the view that it was only North Europe that had the cultural preparedness to develop technology. He attributes this privilege to the new conception of time that northern European monasteries initiated during the Middle Ages, which in turn had given rise to a mode of life that was orderly, regimented and punctuated (Mumford, 1934: 12-13). Other regions of the world, Mumford contends, might have been responsible for developing certain technologies or machines but it was the West that "created" the machine for it had established the necessary socio-cultural and ideological preparation for it. The upshot of it all is that other regions might have machines but the machine has been realized in the West (Mumford, 1934: 15-16). This conception presumes that should any society develop the technological capability that the West developed, it must be because it has by then adopted the social and cultural setting that distinguishes the West.

Almost after fifty years a similar stance was adopted by Ihde (1990). Don Ihde, an American philosopher of technology, argues that since technologies are culturally embedded, their mobility is determined by the cultural contexts in which they were originated and/or to which they will be implanted. A trouble occurs when the receiving society is attempting to pick a new technological artifact without any cultural preparation. This is especially the case - Ihde qualifies - with complex technologies (Ihde, 1990: 137). ${ }^{4}$

In his discussion regarding cultural contexts, Ihde seems to be referring both to the culture in which a technology is developed and the culture that "receives" it. However, ultimately, Ihde's analysis ends up emphasizing the place where the technology was designed and produced. In this regard, in view of Ihde's

\footnotetext{
${ }^{4}$ A portable calculator, for example, calls for some level of mathematical competence for a person to use it in contrast to simple children's toys (Ihde, 1990: 137).
} 
interpretation, societies that import technologies do not seem to have any alternative other than to passively installing them. Eventually, "technologization" would be Westernization. Faithful to this logic, Ihde assumes that certain regions of the world would find it difficult to acquire technologies if they have a rigid policy of rejecting Western values: "Technology-culture transfer in the context of those cultures that firmly reject many Western values becomes a more serious problem" (Ihde, 1990: 138). Like Mumford's view, this theory of "technologyculture transfer" of Ihde's suffers from a cultural determinism that privileges the cultural context in which technologies are designed and produced. This deterministic point of view therefore represents cultural transfer as a one-way traffic, or as something that solely involves - using an expression by Latrell (2000: 45) - a cultural "monologue" that tends to muting or disempowering the society receiving technological achievements. This has been proved wrong, however. As shall be explained shortly, using (like designing and producing) technologies is culturally shaped too. (Hence my topic "cultural translation of technologies.")

What then is the way out of this cultural determinism? Arnold Pacey's notion of "dialogical" relation between technology and culture can be a useful, though tentative, diagnostic tool to clear the fog. For Pacey (1990), technological capability of societies comes from interactions or "dialogues" between technical capabilities on the one hand and cultural traditions on the other. Of course, Pacey adds, the level at which the dialogue is articulated differs in accordance with the technical knowledge of the people introducing the technology. He relates:

This process [technology 'transfer'] can be characterized as a 'dialogue', but how it proceeds must clearly depend on the knowledge and skill of the people who are encountering the transferred technology for the first time. When these people are already developing related techniques, their dialogue with the new technology is likely to be especially creative. If they have no relevant experience, but are nonetheless interested, they may still respond in the manner of a dialogue even if largely in nontechnical ways, perhaps related to social arrangements for use of equipment. Either way, the experience, skill and inventive imagination which people contribute from their own cultural background is crucial. (Pacey, 1990: 204; emphasis added)

This argument may therefore help to correct the theory of cultural preparation discussed above. In line with Pacey's interpretation, we can then argue that any culture adopting new technological artifacts would respond actively. Put 
differently, it "reconstitutes" or "appropriates" new technological artifacts in a way that is befitting its codes. Mobile phones in Africa are used (or "domesticated") in a different way compared to, for instance, how a European or Japanese cultural setting could do because the level or nature of culture-technology dialogue differs from place to place (Setargew, 2016).

However, Pacey's conceptualization is still flawed in some sense. Although his idea of "dialogue" leaves room for creativity and hence for appropriation, the very fact that he still spoke in terms of "transfer" weakened the edge of his argument. The term "transfer" implies passive reception on the part of societies that import or consume technologies. In fact, according to Michel de Certeau (cited in Saglia, 2002), any consumption is a form of production. Drawing on de Certeau's analysis, Saglia (2002: 97) points out: "consumption is not a mechanical process as it amounts to a recreation of the consumed objects in a variety of different contexts. Every act of consumption constitutes a new production by the individual consumer..." (emphasis added).

Within the tradition of technology studies, the term "domestication" has been employed widely since recently in order to capture how technological artifacts could be used in certain social and cultural contexts. According to Silverstone and Haddon (1996), the act of domesticating technologies takes various dimensions. This includes what I called at the beginning of the first section appropriation or reconstitution, a notion aptly depicting the way new technological artifacts at about the end of the $19^{\text {th }}$ century Ethiopia began to find suitable places in the socio-cultural context of the time.

At the other end of the spectrum, which might be described as "technologyculture dialogue" (Setargew, 2016), there is an act of translation (in this case I am speaking of cultural translation of technologies) which I prefer to qualify as "foreignizing" in contrast to domestication. Whereas domesticating a given technological artifact means to take the technology closer to the context (such as, as we shall see shortly, "translating" an airplane as air-mule), foreignizing is an act of readily allowing changes that the script put into the artifact at the design stage was intended to effect. As much as we contravene or circumvent built-in blueprints of a technology, we also happen to be dictated by them and let ourselves be configured in the manner akin to those who design and/or produce the technology had in mind. As shall be pointed out very well in the discussion at the end, there are various forms of "communication" or "translation" in between these two endings of the continuum. 


\section{Historical Context: "Modernization" in Ethiopia}

The history of modern Ethiopia started around the mid- $19^{\text {th }}$ century out of the debris left from the internal regional power rivalries that stayed for almost a century. This period, commonly known as Zamana Mesafint (Era of the Princes), was characterized by a renewed interest of Europeans to visit Ethiopia after the expulsion of Jesuit missionaries in the first half of the $17^{\text {th }}$ century. At this junction of Ethiopian modernization endeavor, Europeans of various trades started to visit the country. Merchants, botanists, experts in natural history, diplomats, and missionaries were among the alliance that entered the country. Side by side with this peaceful engagement, Ethiopia had also been the target for series of Mahdist aggressions. Thus, until 1855, a year for the coronation of Kasa Hailu as Emperor Tewodros II, Ethiopia was sandwiched between internal civil wars and external incursions (Bahru, 2002a). ${ }^{5}$

Once Tewodros came to power, he began to envision few projects in order to modernize the country. The American historian Donald Crummey aptly put the modernizing zeal of the emperor thus:

Here we have an idea distinctive in Ethiopian history, and one which deserves, in the strict sense of the term, the use of the word 'modern'. The idea that Ethiopia should emulate the technological achievements of Europe is one which sharply distinguished Tēwodros from his predecessors amongst the Masāfint, and, indeed, amongst the emperors. (1969: 462)

This came out well in his plan to organize modern standing army (as well as in realizing it at some level) (Caulk, 1972; Keller, 2005: 90). Like many other rulers before and after him, Tewodros was eager to acquire modern armaments. His was, however, unique ${ }^{6}$ in his determination for technological modernization, which was revealed particularly in his keen interest to develop or produce modern arms locally. This was followed by his action of forcing Europeans who were under his custody to produce modern artillery. (Subsequently, the same workshop

\footnotetext{
${ }^{5}$ Whether Tewodros's reign had minimized the internal conflicts has always been controversial - the alternative narrative that it in fact escalated the conflict might not be completely untrue (see Molvaer, 1998).

${ }^{6}$ According to Merid (1984: 130), Lebnä Dengel (r1508-1540), who had a great number of European assistants, had the opportunity to learn about types of weapons Europeans used but didn't show the slightest interest to enquire "if any of the large number of Europeans and other foreigners living in his court could reproduce some of them for him." 114
} 
where the artillery was being made was also serving to train modern Ethiopian soldiers.) Unlike his predecessors, who had been importing guns or tend to simply acquire them when they had the chance to get foreign assistance, Tewodros was very determined in acquiring technical capability (Bahru, 2002a: 34; see Merid, 1980 for a history of firearms in Ethiopia).

However, despite his zealous interest of transforming Ethiopia, Tewodros was not able to move forward on his modernization track. The clergy, on one side, and the resistance of a few regional powers on the other, were formidable obstacles for his endeavors. But more importantly Tewodros's modernization fervor did not come to fruition because, as many scholars of Ethiopian history would say, his ideas ${ }^{7}$ were ahead of his time and did not, therefore, find a fertile soil on which they could grow. In a way reminiscent to what Lewis Mumford said of "cultural preparation," the historian Crummey attributed the failure to lack of important socio-economic and administrative infrastructures:

... he [Tewodros] lacked any social or institutional base upon which to build: national unity eluded him; there was no historic bureaucracy; no national administration had survived the division of the country; urbanization was practically unknown (except, perhaps, in the most rudimentary form); there did not even exist a well-developed class of feudal nobility; and finally, foreign assistance was not forthcoming on a scale at all relevant to the country's needs. $(1969: 465)^{8}$

The other influential emperor after Tewodros, Yohannes IV (1872-1889), was preoccupied with reunifying the country and evangelizing activities. But a great deal of his time and efforts were also spent on defending Ethiopia from a series of foreign incursions. (Thus, another modernization gesture was not rekindled until Emperor Menelik ascended to the throne.)

\footnotetext{
${ }^{7}$ Other than the emperor's interest to establish a modern standing army and the urge to produce arms locally, he was also known for conceiving "the idea of a united, strong, and progressive Ethiopian state" (Sven Rubenson quoted in Samatar, 2003: 31) vis-à-vis increasing pressure from European imperialist powers of the time.

${ }^{8}$ One may also note that the already existing rudimentary urban nucleus (a town like Gondar) did not help the emperor for he had overriding political reasons not to. Some writers even claimed that he wanted to move away from existing urban centers. Aleqa Tekle-Iyesus (Molvaer, 1998: 50), who was known for his apparently hostile depiction of Tewodros, pointed out that the emperor had vandalized the town of Gondar.
} 
Soon after Emperor Yohannes's death in 1889 when he was heroically defending his country, Menelik came to the throne. Menelik had, of course, been consolidating his power since 1865 - a year in which he came to power as ruler of the central province of Ethiopia, Shewa. Emperor Menelik was able to further accomplish the task of reuniting Ethiopia, a project initiated by his predecessors. By then, he was able to extend his reign to the southern and south-western parts of the country. Thus, at the moment he became emperor, he had a broader political and economic bases than most of his immediate predecessors.

The Italian colonial ambition in the Horn of Africa and its subsequent defeat at the battle of Adwa (1896) gave Menelik extensive international recognition. The political and symbolic significance of the victory of Adwa was immense, a victory that rang internationally, calling for an emancipation of colonized people around the world (Bahru, 2002a). This was later to have great ideological and political gains for Ethiopia. But, more importantly, the end of this colonial ambition, and, with this, the end of other potential and actual foreign incursions, gave Menelik ample opportunity to develop his country; hence his modernization efforts. The beginning of the twentieth century marked the beginning of modern education system in Ethiopia. Modern communication technologies such as telephone, telegraph and the printing press were then introduced (Garretson, 2000).

Despite the power struggles that ensued after Menelik's death in 1913, Emperor Haile-Selassie (after being regent and then de facto emperor for sometime) came to the throne officially in 1930. At the time he was regent (then known as Tafari Makonnen), Haile-Selassie had traveled to Europe and visited institutions, including schools, hospitals and factories. On the basis of the foundation established by Menelik, Haile-Selassie proceeded to expand modern education in Ethiopia. Modern schools were opened in the capital city as well as in some provinces. The political power Haile-Selassie forged at the centre was autocratic and equipped with all the necessary bureaucratic and administrative offices. Haile-Selassie had therefore a far better socio-economic and infrastructural preparation in order to resume and run the modernization project that Tewodros and Menelik had launched (Bahru, 2002a).

\section{Cultural Reconstitution of Technologies}

Having roughly set out the historical context within which we can talk about the introduction of new technologies in Ethiopia, I can now proceed to discuss the adoption of these technological artifacts and how they were reconstituted to the traditional cultural milieu of the country. I begin by examining Menelik's endeavors. 


\section{Menelik's Modernization Efforts}

Immediately after the victory of Adwa in 1896, Menelik resumed his task of developing and modernizing Addis Ababa. Historical accounts show that this historic victory had its decisive contribution to the economic, diplomatic and political significance of the capital. Import-export trade expanded. This was facilitated further by the installation of telephone and telegraph lines. The emperor's plan to build railroad attracted foreign capital. Foreign diplomats opened their embassies in the newly established capital city (Garretson, 2000).

The establishment of Addis Ababa as a capital had important implications to the modernization of Ethiopia as a whole. As the settlement steadily grew, Addis Ababa became an attraction to many foreign traders, mainly Arabs, Greeks, Armenians, and Indians. The newly founded capital therefore became not only the political and administrative hub of the country but also the center of commercial transactions.

Addis Ababa had also a larger political and symbolic significance. In relation to this, Pankhurst writes:

The event, which was important in modern Ethiopian history as a landmark in the reorganization and modernization of the State, is not without interest in the wider perspective of the African continent where it provides a unique example of rapid urban growth in an area not under European control. Whereas in such areas the capital was the result of an attempt to create a European type of city in a colonial environment, Addis Ababa represented an attempt by an African ruler to forge something new in his country's history by grafting modern institutions on a traditional living organism. (1961: 103)

And yet, building new (European-like) palace complexes, schools, roads (that would connect the capital to provincial administrative seats), etc. called for foreign expertise. In addition to expatriate artisans already engaged in different activities, Menelik imported additional skilled labor from European countries. Pankhurst relates:

Addis Ababa differed from Entoto and other earlier capitals in that Menelik made far greater use of foreign skill in its construction. Impressed by the need to import technicians from abroad, he had arranged with a Swiss trader in Aden as early as 1877 to procure young European Technicians who would be employed as government engineers and instructors to Ethiopian workers. In the following year three Swiss 
engineers arrived in Shoa, one of whom, Alfred Ilg, was destined to play a notable part in the modernization of the country. (1961: 108)

Ilg had been one of the principal persons who played crucial roles in overseeing some of Menelik's projects. Ilg assumed important responsibilities in designing and building some of the long enduring public buildings to recent times. Moreover, Ilg's contribution to the installation of piped water supply to Addis Ababa, being among the first modernization projects, bore his innovative imprints. His major involvement was in Menelik's railway project. Ilg won a concession from the emperor for the construction of the railway which was later to be known as Djibouti - Addis Ababa railway (Shiferaw, 1991: 351). ${ }^{9}$

But the 'architect' behind all these projects, of course, was the emperor himself. Once he organized the preliminary bureaucratic and administrative facilities that a modern state would call for, Menelik thoughtfully invested in introducing new technical capabilities. As Bahru (2002b) pointed out, already by the end of the $19^{\text {th }}$ century Ethiopia was connected to the rest of the world through a postal and telegraphic network. In 1894, Ethiopia then joined the Universal Postal Union (Ghelawdewos, 2006, para.18). Menelik was very much eager and willing to try any technological equipment that he thought would be useful for his country. In fact, as some historical accounts note, the degree of involvement that the emperor had was that of an innovator's. Drawing on accounts of European travelers who met Menilik, Pankhurst notes:

There can be no denying Emperor Menilek's significance as an innovator. "His chief interest", according to the British traveler Herbert Vivian, was in "mechanical contrivances", about which he had "almost the knowledge of a specialist". The Austrian technician Willy Henze took a similar view, declaring that in Menilek the world had lost a valuable engineer. The Italian envoy Lincoln de Castro likewise observed, humorously, that if a builder of castles in the air came along proposing to build an escalator from the earth to the moon, Menilek would have made him build it, if only to see whether it could be done. (Pankhurst, 2003)

\footnotetext{
${ }^{9}$ As Shiferaw (1991) painstakingly detailed, the initial stages of the railway construction involved complex financial, legal, political and diplomatic issues to the degree that threatened the sovereignty of the country in the face of European powers such as France, Britain and Italy.

118
} 
In fact, as the Austrian technician quoted by Pankhurst stated, there was an engineer in Menelik's person in the sense that, as is the case with professional technologists, he had the tendency to seek technical solutions when he encountered problems. As will be seen shortly, this same assessment (i.e. representing Menelik as an innovator, modernizer) reverberated in the works of Ethiopian and Ethiopianist writers. Nonetheless, quite a few writers (Garretson, 2000; Gebrehiwot, 2010) saw an overstatement in this portrayal - a point I will touch upon later. It is now time to begin discussing the specific technological systems and artifacts that Menelik introduced. (Later on, we shall also embark on cases from emperor Haile-Selassie's period).

\section{Piped Water Project}

As pointed out earlier, immediately after the victory of Adwa, Menelik was engaged in rebuilding and expanding his palace. A number of churches were also constructed in the new capital (Gebreselassie, 2016). He had employed foreigners for the purpose at hand. But since palace building was an age-old tradition in Ethiopia, one cannot really say that the building techniques applied on the palace were all new to Ethiopians. The history of construction in Ethiopia was linked inherently to the tradition of building churches and palaces. Thus, what drew the attention of many residents of Addis Ababa at that time was not the building of palace complexes. What attracted a great deal of astonishment was the construction of piped water supply, for this was completely new to Ethiopia. Pankhurst (2002) notes:

This created something of a sensation, as the water, obtained from a spring in high Entoto, had to flow down to the Addis Ababa plain beneath it, and then make its way up again to the palace compound, which was located on a smallish hill. People in the capital had never seen anything like this, and could not believe that water could ever, under any circumstances, flow upward.

Menelik then encountered resistance from some corners, especially from the clergy establishment. But, more importantly, since people at that time had only a marginal perception regarding mechanical power, they believed that it was only natural for water to flow down a slope of inclined surface. Were water to gain the power to gush "upwards," people reasoned, it must only be engendered by some particular supra-natural power. 
However, the reactions were not completely negative. The piped water was an object of fascination, too. Many people wondered as to what kind of force was instrumental behind this nearly-miraculous performance. A popular couplet at the time reflects this fascination:

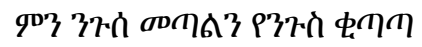

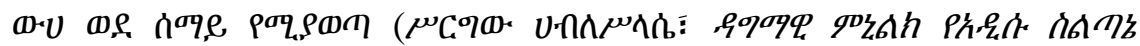
oDhlot: 19 357)

What a king we have got

Who lifts water upwards. (Translation mine)

As Ihde (1990) points out, people would be allured when they encounter a technological system or artifact for the first time. If what the technology can do is easily "readable," like the spectacle of the water going up to the hilly location of the palace, people would switch to raising technical questions such as "How on earth does this happen?" "What helps push this water upwards?" "Would the water be potable?" etc.

Surely, residents of Addis Ababa must have asked similar questions. It is only natural for people anywhere in the world to engage something novel in such a manner. But the questions they might have raised would largely have a "religious" twist and tone than taking a "technical" or "scientific" bent because of the religious, educational, and economic setting working at that moment. When it comes to the clergy, as could be the case in many societies (e.g. Europeans at the time of the absolute domination of the Church - see Hård \& Jamison, 2005), their response to most of the artifacts introduced by Menelik was disparaging. They were mostly quick to depict these new elements as functions of "the devil's machination" (Paulos, 1992; see also Garretson, 1980).

However, it must also be noted here that this reaction should not be dismissed as mere "resistance." Rather, it might or should be taken as one way of culturally appropriating a new technology. An attitude of indifference might in fact be more inimical to an innovation than calling it demonic. The latter is an act of recognition and hence a way of appropriating (though somehow frostily) or placing the new technology in the context of the receiving culture.

That was why this same framework of interpretation had also been employed in order to positively reconstitute the technology. People started to compose and recite poems that commend, praise, and at the same time attach religious meanings to the projects of the emperor. At this junction, pointing out the rich and long 
tradition of composing poetry in Ethiopia would help further to shed light on the present discussion. Either in happy or sad moments, ordinary people would compose poems to express their feelings. They use couplets to define new things. Major historical events of national significance such as coronation of emperors, battles, decisive victories on battlefields, drought and famine periods, etc. would be captured poetically (see Fekade, 2006). A whole account of one major battle could be retrieved on the basis of poems composed in retrospect or at the time of the battle.

Menelik's water project was thus the subject of many impromptu lyric compositions. Here is one of them:

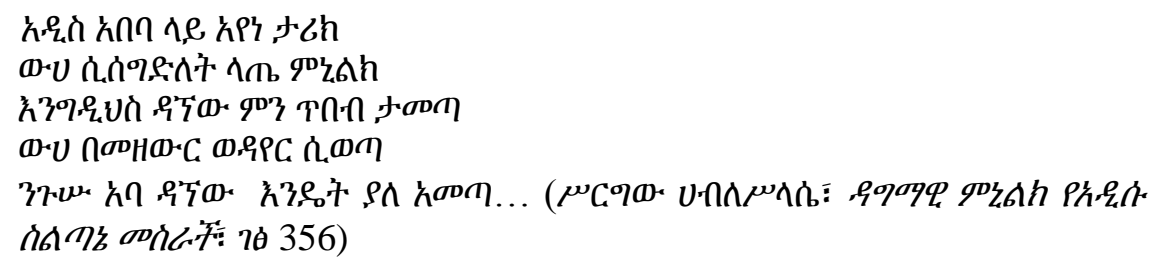

We have seen wonders in Addis Ababa,

Water worships Emperor Menelik.

$O$ Danyew [i.e. Menelik] what more wisdom will you bring?

You already make water soar in the air! (Translation by Pankhurst, 2002)

Layers of meanings surface in this couplet. The first is: what had happened was something miraculous. In fact, the theme of miracle generally coheres into many other religious traditions too. But what we see here is an attempt to understand the new thing in the familiar religious way. For Addis residents of the time, Menelik had been able to do wonders. The storyline is: water, assumed to be one of the unbending forces of nature, was manipulated by Menelik; he made it "soar in the air" against the laws of nature. Water worshiped the emperor!

The second element that the poem tries to impart is that, what had happened was not something that appeared fortuitously. Wisdom was behind its emergence. The matter at hand was not something inexplicable. It was not something to be dismissed once and for all as a near-impossible situation. It was rather something that emanated from astuteness of the emperor. The poem even marvels, though in a tone that combines both awe and expectation, what more wisdom the emperor would bring to the country! 
It is also likely that the person who composed it might have wanted to flatter the emperor. It is important to note at this point that there has been a longstanding tradition of criticizing emperors and personages loyal to them by qenie masters, azmaris, shepherds, and skilled mourners. ${ }^{10}$ Couplets and lyrics may have therefore hidden meanings such as to make a mockery of a king, instrumental to indicate society's disapproval of his policies and practices in a disguised form. Thus, the couplet in question might have a satirical intent, conveying the message of the clergy that it was the devil himself that was using the emperor.

A more matter-of-fact poem was also composed:

King Abba Danyew [Menelik], how great is he becoming!

He makes the water rise into the air through a window,

While the dirty can be washed, and the thirsty drink.

See what wonders have already come in our times,

No wonder that some day he will even outdo the Ferenje [i.e.

Europeans]. (Translation by Pankhurst, 2002)

This poem was not, of course, composed merely to praise Menelik. It seems to have three interconnected meanings. The first is a symbolic one in that it confers prominence and magnificence on the king. It asserts that Menelik is a great king due to the new technological capability that he introduced to the country.

The other meaning expresses a yearning for a time when the country would excel many, especially Europeans. As far as technological modernization is concerned, Ethiopians (probably also many other people around the world) took Europe as the measure or ideal example one should follow. ${ }^{11}$ The poem weighs Menelik's power in terms of what Europeans had achieved because that was the standard against which people measured the country's accomplishments.

The poem also establishes the use-context of the new technological system. That is, we see the poem stressing how this new way of drawing water could actively facilitate things. And more importantly, when the poem stated the obvious (i.e. that people can wash clothes and satisfy their thirst), it was in a way giving the assurance that people can use the water with less fear.

\footnotetext{
${ }^{10}$ Emperor Tewodros was known to have punished azmaris who composed verses critiquing his actions (Molvaer, 1998: 13-14).

${ }^{11}$ Kebede Mikael, a prominent Ethiopian writer and poet, in his book Ethiopia and Western Civilization (1949), underlined that Ethiopia could only grow if and only if she would take Europe's path.
} 


\section{The Introduction of the Telephone}

The telephone was introduced in Ethiopia in 1897 (Garretsson, 1980: 59). Its installation and subsequent expansion acutely demonstrated how new technological systems and artifacts could be culturally reconstituted while at the same time mediating or co-shaping the political power of an emperor who succeeded not only to protect the territorial integrity and sovereignty of the country but also consolidate a functioning central administration. The introduction of the telephone, internationalizing the already existing postal system and other new communication means had further boosted the power of the central government at home and facilitated diplomatic relations with the outside world.

The introduction of these communication systems was not without any difficulty, however. There was a big and open resistance on the part of the clergy. Thus, as Pacey (1990) would say, the "dialogue" or "conversation" between a new technological artifact (in this case, telephone) and the cultural context in which it just began functioning was very arduous. As regards the postal system, there were less hindrances implementing it in the country. Many Ethiopian emperors before Menelik were using postal mails to communicate both within and outside the country. What may be new to the country (as could be the case also to many other countries around the world) was its membership in a global postal association, and the beginning of an efficient and systematic mail circulation on regular basis. As a country with a long written tradition by then, however, using postal mails to exchange information was not something novel. By the time Ethiopia joined the international postal system, the country had the whole apparatus of, to use Ihde's (1990) concept, "reading" and appropriating it.

In the case of the telephone, however, there was initially a "translation" problem. But this should not be taken as something unique to Ethiopia. Telephone, being invented in 1876, reached Ethiopia after only a short period (about 14 years). In the country where telephone was invented, it took some years before it came to be used by the wider public (Fischer, 1994; Casson, 1997). Ethiopia must have therefore been one of the few countries to have telephone lines at that time. If there were negative reactions on the part of society, it should not be regarded as something unexpected.

Let us then have a brief look at the reactions of people. This will help us to see how the technology was received and reconstituted into the Ethiopian cultural context. The first incident was when Ras Makonnen ${ }^{12}$ brought a telephone

\footnotetext{
${ }^{12}$ Ras Makonnen, the father of Ras Tafari (the future emperor Haile-Selassie), was one of
} the generals of Menelik and governor of the eastern town of Harar. 
Setargew Kenaw

apparatus when he came back from a short visit to Europe in 1889 (Paulos, 1992; Garretson, 1980: 60).

Once Menelik acquired this apparatus, he ordered one French technician to operate it. After assuring that the telephone wire was stretched between two halls in the palace compound and started functioning properly, the Frenchman handed over the receiver to the emperor and the latter heard the voice of one of his palace officials. His first reaction, albeit acting a bit frantically, was to drop the receiver on the table and walk to the window in order to check whether the voice he heard on the telephone line was coming from the officer when he was only standing outside the house, making a silly prank (Paulos, 1992: 258). But that was not the case. Menelik found out that the person talking to him was actually talking to him through the wire while being in another building which was far removed from the room where he was. ${ }^{13}$

Subsequently, the offices in the palace were connected by telephone line. This was soon followed by a strong opposition from the Ethiopian Orthodox Church. As Paulos Ňoňo (1992, see also Garretson, 1980: 60) accounted, a contingent of priests was sent to the palace to voice the opposition of the Church. The Church condemned the device as the work of the devil and insisted that it should be discarded.

Nonetheless, as already suggested earlier, this opposition might not be so much because of conservatism as it was an attempt to define and place the new "thing" in context. Similar reactions were abounding in the country where the telephone was developed. The telephone was at first associated with witchcraft in the United States. Casson wrote:

\footnotetext{
${ }^{13}$ This was something which happened to most people who stumbled on the technology immediately after its invention. In his book The History of the Telephone, Herbert N. Casson, gave the following account of the reaction of Dom Pedro, Brazilian emperor visiting the US when Alexander Graham Bell was displaying his invention: "A wire had been strung from one end of the room to the other, and while Bell went to the transmitter, Dom Pedro took up the receiver and placed it to his ear. It was a moment of tense expectancy. No one knew clearly what was about to happen, when the Emperor, with a dramatic gesture, raised his head from the receiver and exclaimed with a look of utter amazement: 'My God -- it talks!'." (1997 electronic version [1911]). Casson added: "People who talked for the first time into a telephone box had a sort of stage fright. They felt foolish. To do so seemed an absurd performance, especially when they had to shout at the top of their voices."
} 
As Bell had worked out his invention in Salem, one editor displayed the headline, "Salem Witchcraft." The New York Herald said: "The effect is weird and almost supernatural." The Providence Press said: "It is hard to resist the notion that the powers of darkness are somehow in league with it." And The Boston Times said, in an editorial of bantering ridicule: "A fellow can now court his girl in China as well as in East Boston; but the most serious aspect of this invention is the awful and irresponsible power it will give to the average mother-in-law, who will be able to send her voice around the habitable glob." (1997[1911])

What made this reaction similar to the one expressed in Ethiopia was its reference to a quasi-religious reason. Witchcraft was invoked as a possible reason behind the working of the telephone. However, this should not imply that the two cultural contexts were similar. The American encounter with the device was actually taking place within a considerable scientific and technological orientation. That was why the allusion to witchcraft was actually brought up with scorns and satires. But then, there were still indications that there was a great deal of confusion among the wider US public. What Casson (1997[1911]) recounts expresses this very well:

The very idea of talking at a piece of sheet-iron was so new and extraordinary that the normal mind repulsed it. Alike to the laborer and the scientist, it was incomprehensible. It was too freakish, too bizarre, to be used outside of the laboratory and the museum. No one, literally, could understand how it worked; and the only man who offered a clear solution of the mystery was a Boston mechanic, who maintained that there was "a hole through the middle of the wire."

However, when put in context, the Ethiopian reaction had a truly religious character. The Ethiopian society, except a few scholars of the Church and the palace, was not literate. Even worse, when measured against the then existing scientific and technological advancement in Europe, America and the Far East, the Ethiopian experience would almost be bare. Hence, it would not be surprising when the response was largely religious. In fact, as stated earlier, though the reaction was negative and inflammatory, the fact that the church took it up as an important issue and tried to explain it in its own terms suggests that the Church was in a way trying to define the device and place it in context by confronting it. Aloofness would have probably done more damage. This can especially be true in 
view of the emperor's counter measure - a point which I consider next.

The emperor's response was immediate. He gathered notable personalities, including the patriarch and addressed it thus:

These priests have become nuisance to me by standing against many of my projects. And now, when I brought telephone, they are arguing against it saying that it is the work of the devil. I have tried my best to convince them that telephone is by no means that of the devil's... They even came here in person to tell me that I should get rid of it. I tried to persuade them that it [the telephone] is not actually the work of the devil. But they do not listen at all. They are simply daydreaming. Thus, I am planning to break my faith [Orthodox Christianity] and convert to another one. This might help me to separate myself from them once and for all. (Quoted in Paulos, 1992: 259; translation mine)

A strikingly similar but shorter account was recorded by another source:

...the priests seem to me cretins. The apparatus works without any kind of diabolical intervention. These priests are day-dreaming. If they go on in this way I will leave them to their religion and become a Muslim! (D. Pariset reporting Menelik's reaction, cited in Garretson, 1980: 60).

This angry response of the emperor then created a great commotion among the nobility and the leaders of the Church. ${ }^{14}$ Given the existing context, it is now natural to assume that Menelik did not actually mean it. (His reaction was of course potentially formidable. Were this translated to practice, in other words, were the emperor to take a practical step in that direction, it would have had disturbing consequences for the status quo.)

Shocked by the response of the emperor, the nobility and the patriarch implored him to drop what he was planning to do, and they assured him in return that the "thing" [the telephone] would be left alone. He was promised that the

\footnotetext{
${ }^{14}$ Since the advent of Christianity in Ethiopia in the $4^{\text {th }}$ century, the great majority (or it might not be a great exaggeration to say "almost all") of Ethiopian emperors were Orthodox Christians. When emperor Susneyos officially accepted Catholicism as his faith in 1621, which was soon followed by a growing number of Jesuit priests, he faced a big social unrest and civil war. He was then forced to resign. His son Fasiledes came to power by retracting what his father had done. He expelled all Jesuit missionaries in 1633.
} 126 
clergy would not stand in his way again.

Subsequently, the capital was connected through telephone wires to some of the provinces and later to the outside world. Drawing on existing accounts, Garretson details:

Menelik exercised his day-to-day supervision over his governors via the telephone, and they had to telephone him about even relatively minor matters. He also checked on the movements of caravans, for many telephone stations were also kéla or customs posts. The results of pitched battles within Ethiopia, for instance the Battle of Koräm in 1909, would be properly telephoned to the gebi [the imperial palace]. Menelik would also be quickly informed of important world events by telegram. (Garretson, 1980: 64)

In a country where the only means of transportation were mules at best, the role of the telephone line was immense. Things that had been taking weeks or months started to be executed within hours, and this in turn contributed significantly to reinforce the power of the central government.

Successive expansion of the telephone lines during the initial years of the reign of Emperor Haile-Selassie had played a pivotal role in dealing with the resistance of regional powers as well as certain political crises in the capital (Garretson, 1980: 64).

The memoire of Leul Ras Emiru Haile-Selassie (a cousin to the emperor and one of the most important officials and notable personalities in Haile-Selassie's regime) documents several crucial telephone communications he had with the central government while he was governor of Harrar, Wollo, Gojjam and Gondar at different times (Emiru, 2009).

Harold Marcus aptly expresses how the telephone was used during earlier period of Emperor Haile-Selassie (when he was only a ras): "The postmasters and telephone-telegraph operators would be the ras's eyes and ears, able quickly to communicate provincial news to the capital" (Marcus, 1994: 119). In his account about the last years of Menelik, Marcus (1994: 108-109) also points out that because of old age and for he had by then lost most of his intimate officials because of natural death, Menelik "governed by telephone."

But the resistance to the telephone was still there even in the $1920 \mathrm{~s}$ (Garretson, 1980: 63). What was remarkable about the two opposing forces namely the clergy that went against the new technology and the emperor that was committed to its installation - was that both appealed to the same set of cultural 
Setargew Kenaw

meanings in order to establish their respective claims. The clergy's claim that the new "thing" was nothing but the seat of the demon was counteracted by a threat of religious conversion, which in turn meant a lot when this was coming from the emperor. But, most importantly, the confrontation in question was more than a mere instance of a set of confrontations of the time. It also reveals the flexibility of the cultural setting to allow choices. After all, the political power of the emperor was very well consolidated to effectively meet the cultural inertia.

Besides, the culture was not simply there to "allow" or "disallow" things. The cultural setting by itself was subject to modification due to the influence of the new technological device. In line with the idea of mediation (see Verbeek, 2005, 2006), the telephone, as a new technological object, was co-shaping the culture in which it started to be part of.

In addition to its functions as communication device, the telephone was very much instrumental in silencing the opposition coming from the Church. The telephone, as a model case, mediated or co-shaped the emperor's struggle with forces that tried to thwart his modernization project. As a result, Menelik was able to proceed with his remaining programs. A railway line had been under construction during his last years (Shiferaw, 1991; Garretson, 2000), which reached the capital in 1917 (four years after the death of the emperor was announced).

Menelik's determination to modernize his country was not limited to introducing artifacts. Along with importing the artifacts, he had been busy with laying down the necessary technical and administrative infrastructure for their functioning. With regard to communication, the establishment of the Ministry of Posts, Telephones and Telegraphs demonstrated early on the emperor's resolve.

The telephone also took its place in society by capturing the popular imagination via couplets and lyrics. An azmari was said to have composed and sang lines that referred to the telephone and train as accomplishments of the emperor thus:

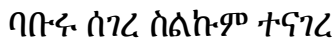

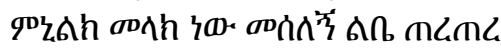

The train canters, the telephone talks

Menelik is an angel, my heart guesses

(cited in Merse'a-Hazen, 2009; translation mine)

On the surface, this couplet represents the train as if it is galloping like a mule 
and personifies the telephone, imageries that were employed to make these new technological artifacts accessible to users who were complete strangers to modern communication means. In passing, these new items had also been used for a purpose beyond themselves. They were made very "translucent" that they had been subjected to mirror the status of the emperor who was behind their installation. Hence the representation of the emperor as angel-like, God's own messenger, or a person with a superhuman capability. While the first sense seems to portray the emperor as a divinely chosen person to carry out the responsibility of modernizing the country, the other conferred on him the authority that no other person than the emperor himself should be in charge because he was the one with a great leadership quality, even in technical matters.

This was of course an extension of the tradition of composing couplets in praise of great men and women, spirits, angels and even God Himself. The following couplet was composed based on the semina worq (wax and gold ${ }^{15}$ ) literary technique utilized to elevate the emperor by comparing him with King Solomon of the Old Testament:

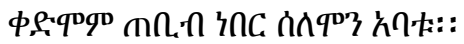

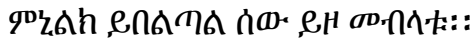

Way back in time his father [King] Solomon was wise

Menelik [his son], however, outshines on account of sharing what he has with others. (Gebreselassie, 2015 [2008 E.C.]: 159; translation mine)

This is recited apparently as an allusion to the emperor's kindness in the context of a geber [royal feast]. It is highly probable that the social event geber is here brought up because of the wealth of meanings it can carry, in this case with an "affordance" to reveal the greatness of the king. The previous couplet, where Menelik is likened to an angel, is also an effort to exalting him because of the new technical capability for which Menelik was believed to be instrumental.

Menelik's figure as a modernizer entered into the discourse of modern Ethiopian literary works also. In his play "Menelik," the poet and playwright Tsegaye Gebre-Medhin considerably displayed this. Here is a small excerpt to show how the emperor's undertaking is represented:

\footnotetext{
${ }^{15}$ The "wax and gold" tradition in Amharic refers to compositions that involve ambiguity and wordplay. Note that the emperor's name Menelik was adopted from the legendary son of King Solomon (whom Ethiopians call Menelik I), whose mother was the Ethiopian Queen Sheba.
} 


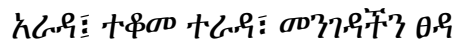

久 久

h

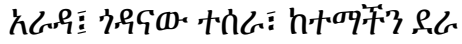

(Tsegaye, 2011 [2003E.C.]: 257)

Arada, rafters are erected, our path cleaned,

Arada, your building is put up, your torchlight glows,

Arada, your edifices are raised, storey laid over storey,

Arada, the roads get paved, our city prospered.

The story recreates what had happened during the foundation of Addis Ababa and provides a romanticized picture of a town, an urban center in the making, retrospectively. Buildings and road constructions were conceived as signposts for creating an urban environment in the new capital city.

A popular traditional song was recorded by Sergew (in an unpublished work):

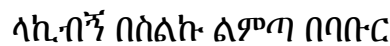

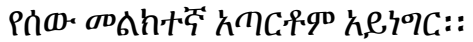

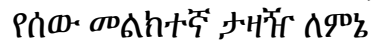

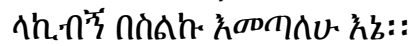

Tell me through the phone so that I can come by train,

As a human courier barely pass a message clearly,

I will come to you as soon as you pass me a clue via the phone,

As I don't really need a human attendant. (Translation mine)

In a way that philosophy of technology has started to characterize since recently, the composer saw in the telephone line its capability to "delegate" (Latour, 1999) a human person, turning the former (the technological artifact) into an "actant" that actively participates in human relations. A human messenger is here described as a less reliable (even distorting) actor compared to the technology.

The following was from one of the popular songs of the 1960s - the time when Westernized Amharic songs got wider reception among urbanized, educated Ethiopians. 
Talk [referring to a male] to me through the thin wire [telephone]

To revisit our shared, beautiful memory. (Translation mine)

No more a subject of rebuke, the telephone entered into the popular imagination and was exalted, conveying messages of love and friendship. Later on, just in a few years, even churches and other religious institutions joined in utilizing telephone lines. An initial example was a direct line that connected the palace and the historic monastery Debre Libanos (Garretson, 1980: 66).

Menelik's modernization efforts were not in fact limited to the artifacts discussed up to now. Because potential foreign aggression was effectively curbed following the victory of Adwa and due to relative peace internally, both foreign and domestic trade was thriving. Modern banking system was in place. Roads that linked the capital to other parts of the country became operational. Traction engines were imported in order to prepare roads that would eventually be used by, first, two-wheeled ox-drawn wagons and later by small cars belonging to notable personalities (Garretson, 2000: ch. 3).

\section{Emperor Haile-Selassie and His Modernization Efforts}

The figure of modernization to follow Menelik's path was Emperor Haile-Selassie I. Until the Italian invasion in 1936, few schools were opened in the capital and the provinces. As pointed out earlier, Haile-Selassie had already been a de facto leader until the death of empress Zewditu as Ras Tafari Makonnen. These years were, however, a period to consolidate his power and create modern state machinery before he became the emperor de jure (Bahru, 2002a).

Tafari bought the first airplanes for the country, which later grew into the Ethiopian Airlines (Bahru, 1988). ${ }^{16}$ One of the notable deeds about HaileSelassie's modernization scheme was that he had been able to ingeniously employ it for consolidating his political power in a degree that was unmatched by his predecessors. The process we call "cultural reconstitution of technology" in general terms could alternatively be depicted here as political reconstitution. It is this aspect of his modernization program that I shall try to examine next. For the

${ }^{16}$ Ethiopian Airlines was the first airline to make east-west flights across Africa in the 1950 's and it has now the largest pan-African network than any airline. 
Setargew Kenaw

sake of restricting the range of the discussion, the focus will be on the process of acquiring the first airplanes.

In 1922 Ras Tafari had the chance to visit British naval fleet in Eden. As the then weekly Amharic newspaper Berhan ena Selam (meaning, Light \& Peace) noted, ${ }^{17}$ they gave the ras a short flight around the port of Eden - the first opportunity for him to get in touch with airplanes. After two years, he visited few European countries including Britain, Italy, and Belgium. He thus came to realize that air transport has become one of the conventional transportation means in Europe; hence his eagerness and determination to introduce airplanes to Ethiopia. This came to fruition in 1929 (Asfaw, 2015: 6-7 ${ }^{18}$ ). Two airplanes were bought and arrived at Djibouti port in August 1929. Now, the question is: how did people then accept or view this matter? How was this new phenomenon accommodated in the existing cultural setting?

Let me begin from the reception that the first airplane had as narrated in Berhan ena Selam. Since this was a government newspaper, the account given will help us to get closer to the emperor's intentions. Berhan ena Selam, issue of August 22, 1929, heralded the news about the first airplane to arrive in the capital in a way that sounded like an editorial and, at the same time, a religious sermon:

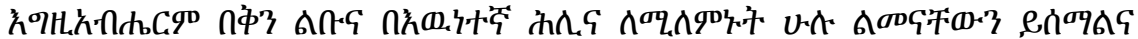

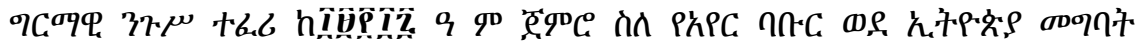

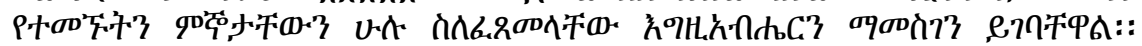

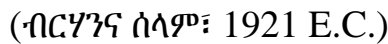

God listens to those who beseech him truthfully and meets all their needs. His majesty [Tafari Makonnen] has been eagerly awaiting since 1917 [E.C.] for the time when the air-train will arrive in Ethiopia. His majesty should now thank God for making his dream come true. (Berhan ena Selam, 1929: 273; translation mine)

\footnotetext{
${ }^{17}$ Most of the accounts concerning the story of the first airplanes to Ethiopia are drawn from few issues of the weekly Amharic newspaper Berhan ena Selam. These issues were published in the last weeks of August 1929 and the first week of September, when the first and second airplanes arrived in Addis Ababa, respectively.

${ }^{18}$ The History of the Ethiopian Air Force (1929-1991) and many other sources (including the Berhan ena Selam newspaper issues employed here and Bahru, 1988) show how intertwined the histories of Ethiopian Airlines and Ethiopian Air Force were. During the movement to Ethiopianize the Airlines, it was the Ethiopian Air Force that trained the pilots to the Airlines (see Asfaw, 2015: 108-109).

132
} 
As already demonstrated when discussing the case of the telephone, it was this religious storyline that was playing important roles in the "reception" of new technological artifacts in Ethiopia. Religion was not only the common ground where people fight over or negotiate their differences but also is an essential cultural instrument employed to approve and endorse new technologies. In the case of the airplane also, the newspaper first and foremost sermonized it as an expression of God's will. The new technological object was considered as an element through which God demonstrated His providence. They believed that through this device God wanted to help the prince, and, through him, Ethiopia.

But the newspaper was also quick to list the functions of the airplane in the "real" world. It accounted that there were two reasons why Tafari decided to import the airplanes. The first was to reach different parts of the country and dispatch official government mails. The second reason that the newspaper stressed was the usefulness of airplanes in fighting swarms of pests covering wide agricultural areas. The newspaper recounted the experience of other countries in this regard, and added that Ethiopia might also be attacked by similar swarms:

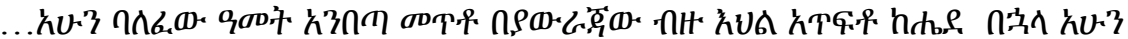

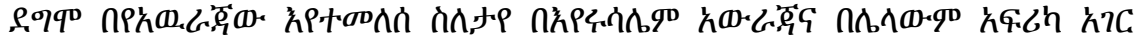

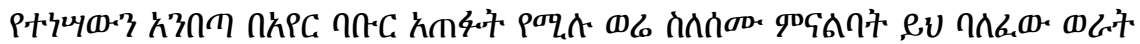

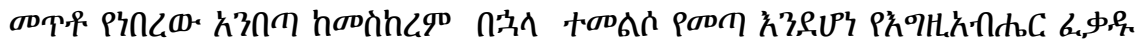

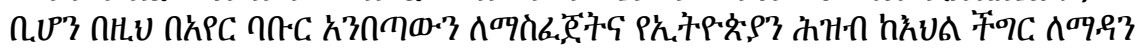

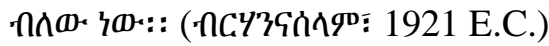

Last year, swarm of grasshoppers destroyed crops in many awrajas (districts); these days also it has started to appear again... We have heard that airplanes were used to avert the problem in places like Jerusalem and some parts of Africa. It is also probable that we might soon encounter a similar problem ourselves. We can thus use airplane to wipe out the grasshoppers and hence protect the Ethiopian people from shortage of crops. (Berhan ena Selam 1929: 273-274; translation mine)

Of course, according to the official conviction of the time, the will of God must be there if the technology is going to function. That was why the clause "if God wills" was added even if the newspaper was discussing the usual, ordinary functions that the airplanes were supposed to deliver. In other words, God's will had been considered as a necessary condition for their functioning. As was the case for the telephone and piped water, the religious theme had been once again the 
dominant interpretive framework in place to appropriate the new technology.

Nonetheless, it must also be clear that pioneer modernizers of Ethiopia like Tewodros, Menelik and Haile-Selassie employed also various other means (other than religion) in order to orient the people about the artifacts they were introducing to the country. Put differently, they were not simply appealing to faith alone. That was what Berhan ena Selam was doing when it was discussing an airplane's role in fighting pests as well as facilitating transportation.

In addition to the "official" welcome that the air transport received, the manner in which it was seen and received by the common people is also worth mentioning here. When the first airplane reached the capital, Addis Ababa, on the $18^{\text {th }}$ of August 1929, the response was unique (Abel \& Pasteau, 1972). People from all walks of life flocked to the field where the airplane was to land, and they waited for hours to witness the event. When the plane arrived at around 1:00 in the afternoon, people were mesmerized by the experience. According to one account, some people lost some valuables due to a distraction. One person had even lost a cartridge belt he wore because he was completely immersed looking up at the plane about to land. (This story was recounted many times after that because losing a cartridge belt (mostly alluded to metaphorically) was regarded as giving up one's masculinity.)

The other form of the reception was naming the airplane as yeayer babur (an Amharic word for air-train); by then the railway was functioning for about ten years. This was, therefore, a way of (re-)defining the function of the airplane. In his speech during the reception of the first airplane in Addis Ababa, Taferri Makonnen had this to say:

We want to give our thanks to those who are here to share our happiness when the air-train arrives in Addis Ababa. We also want to thank Monsieur Maillet for navigating the air-train for the first time all the way from Djibouti to Addis Ababa... (Merse'a-Hazen, 2009: 372; translation mine)

The wider public also was using this expression for some time to come after that. But there was another and more interesting name that the airplane came to be known with, namely yeayer beqlo (an Amharic term for air-mule). This has culturally and symbolically a more powerful message to Ethiopians. The mule had been (and still is in many rural areas) the major means of transportation. The mule can gallop for hours on very difficult terrains. Because an airplane, like the mule, can also help overcome the difficult physical terrain, the plane was immediately 
defined and understood in the Ethiopian cultural terrain; thus the designation airmule.

As said, Emperor Haile-Selassie was therefore one of the pioneering figures to modernize the country. He was very much instrumental for the expansion of modern education in Ethiopia. He was able to organize a modern army par excellence. He created an airline that was to become the leading airline not only for networking Africa but also to connecting the continent with the rest of the world. He had established highly successful international diplomatic relations. He was one of the founding fathers of the African Union (known before as the Organization of African Unity) for which Ethiopia's capital Addis Ababa has been the seat ever since.

On the basis of his endeavors to forge strong international relations, and, above all, because of his efforts to expand modern education and open the door for new technological artifacts, Emperor Haile-Selassie was popularly known as tsehayu negus ("the sunny emperor") - a naming that went back to the few years he was a ras under Zewditu. Thus, in addition to, and somehow also associated with, the religious legitimization that his political power drew on, the emperor was able to formulate the symbolism that revolved around his modernization efforts. When he named the newspaper Berhane ena Selam (Light \& Peace), it was deliberate on his part. Under the title of the newspaper we find the following description: "His Majesty Tafarri Makonnen ... named this newspaper as Berhan ena Selam out of his sheer desire that light and peace be in his country."

This had been a recurring theme attached to so many things. According to Shiferaw Bekele ${ }^{19}$, a professor of history at Addis Ababa University, the emperor was tirelessly and carefully forging this symbol for the sake of consolidating and legitimating his political power. His coronation ceremonies were always glittering with new things imported from Europe. He was always seen on television and newspaper cover pages inaugurating factories, schools, etc. The emperor was in effect saying "I am your light," "I brought you education, technologies," etc.

Newspaper columns, radio programs, television broadcasts and educational materials had reflected this point of view. In this regard, the very technological systems and devices that the country was able to import were also used to ensure and reinforce the political, socio-economic, and diplomatic vigor of the emperor. More importantly, the fact that people were coining local terms, composing songs and poems in praise of, or simply alluding to, the new technologies contributed to

\footnotetext{
${ }^{19}$ Personal communication, May 2006, Addis Ababa University
} 
Setargew Kenaw

the cultural translation or, to use Schneider's (2003: 222) term, "cultural construction" of the technologies in a setting in which they might have been at odds with at first.

\section{Conclusion}

All the cases analyzed so far demonstrate that technology transfer would not necessarily be instances of cultural transfer in the sense that the culture in which the technology was developed would be transferred along with the technology that it exports. Such a view readily assumes that if a given part of the world imports technologies from another, the receiving society would be forced to submit to the culture that manufactured the technology as though the former would be nothing but a passive receiver. Contrary to this deterministic view (discussed in the first few pages of the article), the meeting between the new technologies and the social and cultural contexts in which the technologies function engage each other at differing levels.

The technological artifacts discussed above were in many ways culturally appropriated. Ethiopians had composed poems glorifying Emperor Menelik for his capacity to make "water flow upwards." Menelik responded to the clergy's objection towards the telephone in their own language, saying that the telephone is the work of the glorious God instead of that of the devil. In this respect, the Ethiopian cultural milieu was able to domesticate and appropriate the new technological artifacts on the basis of already existing cultural and religious codes. Besides, the emperor had established a consolidated political and ideological power to confront thwarting forces. He was able to impose the new technologies and that with great passion. But, more importantly, he also managed to exploit the cultural resources for his modernization projects. By fighting back on the basis of arsenals he obtained from the religious tradition of the country, the emperor was able to vigorously advance his initiatives. When it comes to Emperor HaileSelassie's time, we even see a more creative use of cultural traditions. HaileSelassie tried to wed his modernization plan with the cultural tradition of the country. (This does not mean that this so-called modernization scheme did not have alienating effect as well - a thought that is conspicuously absent in this article.)

The major line of argument I am following here underlines that there is some kind of dialogue, "conversation" between the technological artifacts that Ethiopia imported before and at the beginning of the twentieth century and the existing social and cultural milieu. As shown, the level of the dialogue of course differs from one encounter to the other. For example, it is likely that the appropriation of a 136 
technology could be merely emblematic. A custom of wearing a wristwatch without having the minimal literacy to read it could be taken as an example of appropriating an artifact at the lowest level because its purpose would at best be decorative. Going back to $16^{\text {th }}$ century Ethiopia and discussing society-technology interaction for the next three centuries, Merid (1984) points out how low the level of dialogue was. Based on a painstaking assessment of sources, Merid contends that it might not be too extrapolating to say that there was a time when a weapon could be owned as a mere "prestige symbol" (1984: 132).

Conversely, the example of the first encounter with the telephone at the end of the $19^{\text {th }}$ century followed a different path: as discussed, it picked up speed in the process of domestication. The fact that there was a huge opposition from the clergy and the skepticism and reluctance with which it was accepted among officials, and, on the other hand, the determination the emperor had to install it, provided a fertile social ground for the new technology. A good example for a higher level of conversation between a technological system and the socio-cultural context under discussion has been displayed in the speedy and steady development of aviation in Ethiopia. The expansion of the Ethiopian Airlines during the past few decades is a clear demonstration of a high level of dialogue between a technology and a social context.

However, a conversation could also fail entirely and, if I am allowed to stretch the metaphor a little further, even slip into non-communication. Thus, certain technologies may face an unresponsive social environment, or a social and cultural setting could silently reject some technologies. In this regard, it must be clear by now that I am not arguing that there had been a wholesale cultural translation of technologies in Ethiopia a century ago. As could be the case with many other societies encountering new technological innovations for the first time, in Ethiopia too there has always been resistance. Merid, drawing on accounts of a traveler in the first half of the $16^{\text {th }}$ century Ethiopia (whom he praises as the "most inquisitive of chroniclers"), affirms that the period was short of any attempt to adopt technologies because "the Ethiopian rulers were bad patrons of skills" (Merid, 1984: 129). Although I am a little bit skeptical of this sweeping generalization, worse still when one is merely relaying the perceptions of some skewed European travelers, Merid's analysis still seems to hold water nonetheless in view of the situation in the time span he was referring to, that was between 1500 and 1800 . In addition to the precluding nature of the land tenure system - to which Merid attributes to as a major obstacle in the way of innovation - the time was for sure punctuated with periodic internal civil wars, a factor that must have probably contributed in sustaining the said standstill. 
It is not thus very difficult to imagine that the translation under discussion must have shown variation in time. But it is also natural that interpretations would vary, some in a distorted way. As much as some accounts could exaggerate, others may undermine. Menelik was taken by many as a modernizer while a few questioned this. At times, the tension is displayed within the same work. Garretson's (2000) monograph on the history of Addis Ababa is a good example. While Garretson offers one of the most comprehensive and detailed accounts on Menelik's measures (including advancing financial institutions and expanding transportation means), he hesitated to represent the emperor's activities as part of a great measure of modernizing the country. In a sheer contradiction to his own documentation, he dared to say that the emperor "encouraged change and innovation not for the sake of modernization but in order to increase his power and prestige or because mechanical gadgets just happened to arouse his interest and curiosity" (Garretson, 2000: 144; emphasis mine). Even Gebrehiwot, who personally witnessed most of the accomplishments of the time and known also for his judicious piece of writings, failed to distance himself from a resentment harbored blanket dismissal of what the emperor accomplished (Gebrehiwot, 2010: 12-13).

Compared to the period Merid and the travelers he draws on depicted, what was initiated in the second half of $19^{\text {th }}$ century Ethiopia could therefore be taken as a movement to "modernize" the country. It is to this effect that I have been trying to conceptualize the country's effort to creatively take up new technologies as an act of cultural translation. Of course, as can be hinted from the discussion so far, this act of translation (if we extend the time to a point where we are now) covers wide range of creative appropriations, ranging from a symbolic-emblematic level to a level that involves assembling, redesigning, manufacturing, etc. The glory that the Ethiopian Air Force had once, and the height of development that the Ethiopian Airlines has attained during the last seven decades - whose embryo was actually implanted in the 1920s - are practical demonstrations for a certain degree of depth that the cultural translation has reached.

\section{Acknowledgements}

Because of the comments of the anonymous reviewers, this essay has benefited significantly. I would like to take this opportunity to thank these amazing reviewers for being instrumental in helping this paper take the shape it has now. I would also like to thank Dr. Abiy Tsegaye, an assistant professor of philosophy, for meticulously editing the final version. 


\section{References}

Abel, A. and Pasteau M.M. (1972). "The arrival of the first aeroplane in Ethiopia." Journal of Ethiopian Studies, 10 (2): 97-103.

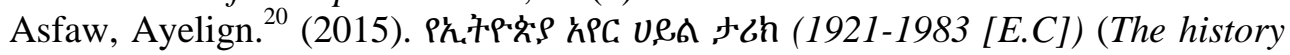
of the Ethiopian Air Force (1929-1991)). Addis Ababa: Eclipse Printing Press.

Bahru, Zewde. (1988). Bringing Africa together: The story of Ethiopian Airlines. Addis Ababa: Ethiopian Airlines.

Bahru, Zewde. (2002a). A history of modern Ethiopia 1855 - 1991, $2^{\text {nd }}$ ed. Addis Ababa: Addis Ababa University Press.

Bahru, Zewde. (2002b). Pioneers of change in Ethiopia: The reformist intellectuals of the early twentieth century. Addis Ababa: Addis Ababa University Press.

Berhan ena Selam. (1929). Berhanena Selam, Year 5, Nos. 34, 35, and 36.

Casson, H. N. (1911) (electronic version 1997). The history of the telephone Retrieved from: http://www.gutenberg.org/dirs/etext97/thott10.txt

Caulk, R.A. (1972). "Firearms and princely power in Ethiopia in the $19^{\text {th }}$ Century." The Journal of African Study, 13(4): 609-630.

Crummey, D. (1969). "Tewodros as reformer and modernizer." The Journal of African History, 10(3): 457-469.

Elizabeth, Wolde Giorgis. (2010). "Charting out Ethiopian modernity and modernism." Callaloo, 33(1) (Ethiopia: Literature, Art \& Culture): 82-99.

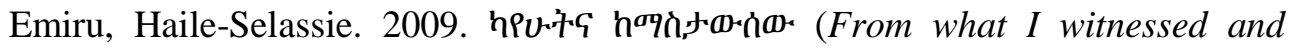
remember). Addis Ababa: Addis Ababa University Press.

Fekade, Azeze. (2006). Unheard voices: Drought, famine and God in Ethiopian oral poetry. Addis Ababa: Addis Ababa University Press.

Fischer, C. S. (1994). America calling: A social history of the telephone to 1940. Berkeley: University of California Press.

Garretson, P. P. (1980). Ethiopia's telephone and telegraph system, 1897-1935. Northeast African Studies, 2(1):59-71.

${ }^{20}$ Ethiopian authors are addressed by their first names. 
Garretson, P. P. (2000). A history of Addis Ababa from its foundation in 1886 to 1910.Wiesbaden: Otto Harrassowitz Verlag.

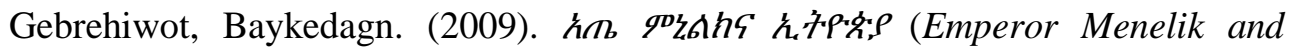
Ethiopia in Gebrehiwot Baykedagn Collected Works, pp.1-28.) Addis Ababa: Addis Ababa University.

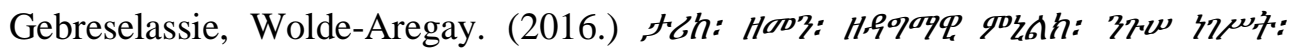
Hh.;P:?:: (The history of Emperor Menelik of Ethiopia.) NP.

Ghelawdewos, Araia. (2006). Emeye Menelik Abba Dagnew: Emperor of Ethiopia. Retrieved from: http://www.africanidea.org/Emeye.pdf

Hård, M. and Jamison A. (2005). Hubris and hybrids: A cultural history of technology and science. New York: Routledge.

Ihde, D. (1990). Technology and the life world: From garden to Earth. Indiana University Press.

Kebede, Mikael. (1949). Ethiopia and western civilization. (Translated by Marcel Hassid.). N.P.

Keller, E.J. (2005). Making and remaking state and nation in Ethiopia. In Laremont, R.R., editor. Borders, nationalism, and the African state. Boulder, CO: Reinner.

Latour, B. 1999. Pandora's hope: Essays on the reality of science studies. Cambridge, MA: Harvard University Press.

Latrell, C. (2000). “After appropriation.” TDR: The Drama Review, 44(4): 44-55.

Marcus, H. (1994). A history of Ethiopia. Berkeley: University of California Press. Merid, W. Aregay. (1980). "A reappraisal of the impact of firearms in the history of warfare in Ethiopia (C.1500-1800)" Journal of Ethiopian Studies.14: 98121.

Merid, W. Aregay. (1984). "Society and technology in Ethiopia 1500-1800." Journal of Ethiopian Studies.17:127-147.

Merse'a-Hazen, Wolde-Qirqos. (2009 [1921]). Р४९ร

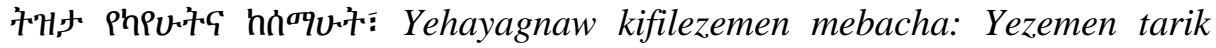
tizita yekayhut ena kesemhaut, 1896-1922 (Early Twentieth Century Ethiopian History Based on Eyewitness and Reported Accounts). Addis Ababa: Addis Ababa University Press. 
Molvaer, R. K. (1998). "The achievement of emperor Téwodros II of Ethiopia (1855-1868): From an unpublished manuscript by Aleqa Tekle-Ïyesus (“Aleqa Teklé") of Gojjam." New Series, 5(3): 7-79.

Mumford, L. (1934). Technics and civilization. New York: Harcourt.

Pacey, A. (1990). Technology in world civilization: A thousand-year history. Cambridge, Mass.: MIT Press.

Pankhurst, R. (1961). "Menelik and the foundation of Addis Ababa." The Journal of African History, II(1): 103-117.

Pankhurst, R. (2002). Foreign involvement in Ethiopia's progress: Alfred Ilg. Retrieved from: http://www.addistribune.com/Archives/2002/12/13-12$\underline{\text { 02/Foreign.htm }}$

Pankhurst, R. (2003). "Menelik at relaxation: Who photographed who?" Retrieved from: http://www.addistribune.com/Archives/2003/05/30-05-03/Menilek.htm.

Paulos Ñoño. (1992). h̆ gמל̌h (Emperor Menelik). Addis Ababa: Bole Printing Press.

Saglia, D. (2002). "Translation and cultural appropriation: Dante, Pauolo, and Francesca in British Romanticism." Quaderns: Revista de Traducció, 7: 95119.

Samatar, Said S. (2003). "Genius as madness: King Tewodros of Ethiopia and Sayyid Muhammad of Somalia in comparative perspective." Northeast African Studies (New Series), 10(3): 27-32.

Schneider, Arnd. (2003). “On 'appropriation': A critical reappraisal of the concept and its application in global art practices." Social Anthropology, 11(2): 215229.

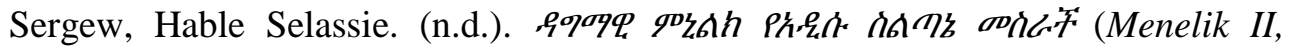
Founder of the new civilization). (n.p.).

Setargew, Kenaw. (2006). Cultural translation of technological modernization: Postphenomenology and technological mediation of culture. Unpublished master's thesis, University of Twente, the Netherlands. https://essay.utwente.n1/59318/1/scriptie S Kenaw Fantaw.pdf

Setargew, Kenaw. (2016). Technology-culture dialogue: Cultural and socio technical appropriation of mobile phones in Ethiopia. Munster: LIT Verlag. 
Shiferaw, Bekele. (1991). "The Ethiopian railway and British financial capital, 1896-1902." Africa: Rivista trimestrale di studi e documentazione del l'Istituto italiano per l'Africa e l'Oriente, 46(3): 351-374.

Silverstone, R. and L. Haddon. (1996). "Design and domestication of ICTs: Technical change and everyday life." In R. Silverstone and R. Mansell, editors. Communication by design: The politics of information and communication technologies. Oxford: Oxford University Press.

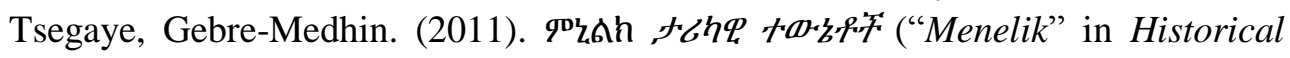
plays) (Pp.122-285). Addis Ababa: Addis Ababa University Press.

Venuti, L. (1995). The translator's invisibility: A history of translation. London: Routledge.

Verbeek, Peter-Paul. (2005). What things do: Philosophical reflections on technology, agency and design. Pennsylvania: The Pennsylvania State University Press.

Verbeek, Peter-Paul. (2006). "Materializing morality: Design ethics and technological mediation." Science, Technology, and Human Values, 31(3): 361380. 